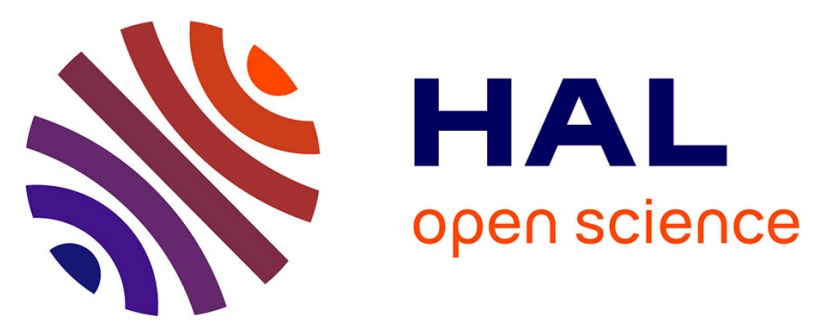

\title{
Post-translational acylation controls the folding and functions of the CyaA RTX toxin
}

Darragh P O'Brien, Sara E Cannella, Alexis Voegele, Dorothée Raoux-Barbot, Maryline Davi, Thibaut Douche, Mariette I Matondo, Sebastien Brier, Daniel Ladant, Alexandre Chenal

\section{To cite this version:}

Darragh P O'Brien, Sara E Cannella, Alexis Voegele, Dorothée Raoux-Barbot, Maryline Davi, et al.. Post-translational acylation controls the folding and functions of the CyaA RTX toxin. 2021. pasteur-03221015

\section{HAL Id: pasteur-03221015}

\section{https://hal-pasteur.archives-ouvertes.fr/pasteur-03221015}

Preprint submitted on 7 May 2021

HAL is a multi-disciplinary open access archive for the deposit and dissemination of scientific research documents, whether they are published or not. The documents may come from teaching and research institutions in France or abroad, or from public or private research centers.
L'archive ouverte pluridisciplinaire $\mathbf{H A L}$, est destinée au dépôt et à la diffusion de documents scientifiques de niveau recherche, publiés ou non, émanant des établissements d'enseignement et de recherche français ou étrangers, des laboratoires publics ou privés.

\section{(ㅇ)(1) $\$$}

Distributed under a Creative Commons Attribution - NonCommercial| 4.0 International 
1 Post-translational acylation controls the folding and functions of the CyaA RTX toxin

2 Darragh P. O’Brien ${ }^{1} \#$, Sara E. Cannella ${ }^{1} \#$, Alexis Voegele ${ }^{1,2}$, Dorothée Raoux-Barbot ${ }^{1}$, '

3 Davi $^{1}$, Thibaut Douché ${ }^{3}$, Mariette Matondo ${ }^{3}$, Sébastien Brier $^{1 *}$, Daniel Ladant ${ }^{1 *}$ and

$4 \quad$ Alexandre Chenal ${ }^{1 *}$

5

6 Addresses

$7 \quad{ }^{1}$ Institut Pasteur, Chemistry and Structural Biology Department, UMR CNRS 3528, 75724

8 PARIS cedex 15, France

$9 \quad{ }^{2}$ Université Paris Diderot Paris VII, 75013 Paris, France

$10{ }^{3}$ Institut Pasteur, Proteomics Platform, Mass Spectrometry for Biology Unit, USR CNRS

112000,75724 PARIS cedex 15, France

12

13 \# these authors contributed equally to this work

$14 *$ to whom correspondence and material requests should be addressed:

15 sebastien.brier@pasteur.fr; daniel.ladant@pasteur.fr; alexandre.chenal@pasteur.fr

16

17 Keywords: post-translational modification, acylation, protein folding, calcium-binding protein,

18 adenylate cyclase, bordetella pertussis, RTX motif

19

20 Running title: Acylation and calcium control CyaA folding

21

22 


\section{List of abbreviations}

24 AC, N-terminal Adenylate cyclase Catalytic domain; cAMP, cyclic Adenosine 25 MonoPhosphate; CyaA, adenylate cyclase; HDX-MS, Hydrogen/Deuterium eXchange 26 followed by Mass Spectrometry; HR, Hydrophobic Region; PTM, Post-Translational 27 Modifications; pro-CyaA, non-acylated adenylate cyclase; RD, RTX Domain; RTX motif, 28 Repeat in ToXin motif; T1SS, Type 1 Secretion System; TR, Translocation Region; 29 
CyaA is synthetized as a pro-toxin, pro-CyaA, and converted into its cytotoxic form upon acylation of two lysines. After secretion, CyaA invades eukaryotic cells and produces cAMP, leading to host defense subversion. To gain further insights into the effect of acylation, we compared the functional and structural properties of pro-CyaA and CyaA proteins. HDX-MS results show that the refolding process of both proteins upon progressive urea removal is initiated by calcium binding to the C-terminal RTX domain. We further identified a critical hydrophobic segment, distal from the acylation region, that folds at higher urea concentration in CyaA than in pro-CyaA. Once refolded into monomers, CyaA is more compact and stable than pro-CyaA, due to a complex set of interactions between domains. Our HDX-MS data provides direct evidence that the presence of acyl chains in CyaA induces a significant stabilization of the apolar segments of the hydrophobic domain and of most of the acylation region. We propose a refolding model dependent on calcium and driven by local and distal acylation-dependent interactions within CyaA. Therefore, CyaA acylation is not only critical for cell intoxication, but also for protein refolding into its active conformation.

Public Summary

The contributions of post-translational modifications on the folding and activity of proteins are still poorly understood. The adenylate cyclase toxin, CyaA, is a major virulence factor of Bordetella pertussis, the causative agent of whooping cough. CyaA is produced as an inactive pro-toxin, which is post-translationally acylated in the bacterial cytosol to yield the active CyaA toxin, able to intoxicate human cells and induces cell death. Yet, the link between this post-translational modification, the structure and the cytotoxic activities of CyaA remains elusive. Here, using Hydrogen/Deuterium eXchange followed by Mass Spectrometry (HDXMS) and a combination of biophysical approaches, we demonstrate that acylation contributes to the proper folding of CyaA into a compact and functional state. Our data sheds light on the complex relationship between post-translational modifications, structural disorder and protein folding. Coupling calcium-binding and acylation-driven folding is likely pertinent for other Repeat-In-Toxin cytolysins produced by many Gram-negative bacterial pathogens. 
Post-translational modifications (PTM) are involved in the regulation of many cellular processes and play a critical role in protein localization, structure, stability and function $(1,2)$. Post-translational addition of acyl chains to bacterial toxins from the Repeat-In-Toxin (RTX) family has been shown to be essential to their cytolytic activities. RTX toxins are calciumdependent virulence factors produced by various Gram-negative bacteria $(3,4)$. These cytotoxins are synthesized as non-active precursors that require "activation" by selective posttranslational acylation carried out by dedicated acyltransferases that use an acyl-acyl carrier protein (acyl-ACP) as fatty acid donor (5-9). Once acylated, the RTX toxins are secreted via dedicated type 1 secretion systems (T1SS) and exert their virulence on a variety of target cells (10). Most are cytolysins endowed with a pore-forming activity that alter the membrane integrity of their target cells $(3,4,11)$ while few others have additional cytotoxic activities (see below). How the acyl chains regulate the biological activities of these RTX cytolysins has remained elusive thus far.

Here we address this question by exploring the effects of post-translational acylation on the structure and functions of the adenylate cyclase toxin (CyaA) from Bordetella pertussis, the causative agent of whooping cough (12). In addition to its pore-forming activity, CyaA possesses an extra domain endowed with adenylate cyclase activity. This AC domain is delivered into the cytoplasm of target cells $(13,14)$ where it is activated by calmodulin $(15$, 16), to produce high levels of cAMP, subverting host immunity $(10,17,18)$. CyaA is a large, multi-domain protein of 1706 amino acid residues (Figure 1), with an $\mathrm{N}$-terminal adenylate cyclase catalytic domain, AC, (residues 1-364) (16), while the C-terminal hemolysin region (residues 365-1706) contains several domains responsible for AC membrane translocation and pore-forming activity (19-24). The translocation region, TR, (residues 365-527) is involved in AC translocation across target cell membranes (24), membrane permeabilization (25) and exhibits features similar to membrane-active peptides $(24,26,27)$. The hydrophobic region, $\mathrm{HR}$, corresponds to residues 528 to 710 while the acylation region, AR, extends from residues 711 through 1005 . CyaA is synthesized as an inactive precursor, pro-CyaA, that is converted into its active form upon specific acylation of two lysine residues (Lys 860 and Lys 983) by $\mathrm{CyaC}$, an acyltransferase that catalyzes the transfer of an acyl chain from an acyl-ACP (acylcarrier protein) to the epsilon-amino groups of pro-CyaA lysines $(7,28-30)$. Finally, the Cterminal 701 residues (1006-1706) correspond to the cell receptor-binding domain, RD, which harbors $\sim 40$ copies of a glycine and aspartate rich nona-peptide repeat, characteristic of the RTX bacterial cytolysins. In the absence of calcium, these RTX motifs are intrinsically disordered, but undergo a disorder-to-order transition upon calcium binding (4, 31-42). The RTX motifs themselves constitute the primary sites of calcium binding within the protein (3, $31,43,44)$.

It is well known that acylation is critically required for the pore-forming activity of CyaA as well as its ability to invade cells to produce high levels of cAMP (i.e., cell intoxication) (45, 
101 and CyaA monomers to provide insights into their folding process, and to identify the 102 structural basis of the acylation-dependent gain of functions. Our biophysical data show that 103 the acylated CyaA protein adopts a more compact and stable monomeric state than pro-CyaA, 104 while Hydrogen/Deuterium eXchange followed by Mass Spectrometry (HDX-MS) studies 105 provided direct evidence of long-range interactions between the hydrophobic and acylation 106 regions. HDX-MS results further indicate that these interactions are strongly favored in the 107 presence of the acyl chains. We propose that these interactions may directly contribute to the 108 folding of the acylated CyaA protein into a compact and functional monomeric state. Our data 109 indicates that calcium-binding and post-translational acylation play a key role in the folding 110 of CyaA into its cytotoxic form. 
113 Overexpression and purification of pro-CyaA and CyaA in urea and production of the 114 monomeric species

115 Buffer A was composed of $20 \mathrm{mM}$ Hepes, $150 \mathrm{mM} \mathrm{NaCl}, \mathrm{pH}$ 7.4. Production and 116 purification of pro-CyaA and CyaA, and refolding of both species into holo-monomers was 117 performed as previously described $(41,47)$. The pro-CyaA urea stock solution was loaded at 2 $118 \mu \mathrm{M}$ (compared to $5 \mu \mathrm{M}$ for CyaA) on a size exclusion chromatography column (HiLoad 119 26/600 Superdex $200 \mathrm{pg}$, average particle size: $34 \mu \mathrm{m}$; column dimensions: 26*600 mm or 120 Superdex 200 Increase 10/300 GL, average particle size: $8.6 \mu \mathrm{m}$; column dimensions: 10*300 $121 \mathrm{~mm}$ or Agilent BioSEC-5, particle size: $5 \mu \mathrm{m}$, pore size: $300 \AA$, column dimensions: $21.2 * 300$ $122 \mathrm{~mm}$ ) to refold the protein into a monomeric species. The monomer-to-multimer ratio 123 increases as the particle size decreases.

124 Identification of the post-translational acylation of pro-CyaA and CyaA by mass 125 spectrometry

$126 \quad$ Protein digestion. CyaA $(9 \mu \mathrm{M})$ and pro-CyaA $(7 \mu \mathrm{M})$ in $6 \mathrm{M}$ urea buffer were firstly digested with Lys-C (\#V1671, Promega) at a Lys-C/toxin ratio of $1 / 50(w / w)$, at $37^{\circ} \mathrm{C}$ for $3 \mathrm{~h}$. To ensure optimal trypsin activity, the urea concentration was decreased below $2 \mathrm{M}$ with addition of 2 volumes of buffer A, then a second digestion was performed with Trypsin 130 (Sequencing Grade Modified Trypsin \#V5111, Promega) at a enzyme/toxin ratio of 1/50 $131(\mathrm{w} / \mathrm{w})$ at $37^{\circ} \mathrm{C}$ for $1 \mathrm{~h}$. Digestion was stopped by adding formic acid to $2 \%$ final concentration. 132 Digested peptides were desalted and concentrated with C18 Spin Columns Pierce ${ }^{\mathrm{TM}}$ 133 (ThermoFisher Scientific - 89870) according to manufactures instructions. Peptides were 134 vacuum centrifuged and then lyophilized. Peptides were reconstituted in $2 \% \mathrm{ACN} / 0.1 \%$ FA.

135 LC-MS/MS analysis. A Proxeon EASY-nLC 1000 nanochromatographic system (Thermo 136 Fisher Scientific, Bremen) was coupled on-line to a LTQ-Orbitrap Velos Mass Spectrometer 137 (Thermo Fisher Scientific, Bremen). For each sample, $0.5 \mu \mathrm{g}$ of peptides was directly loaded

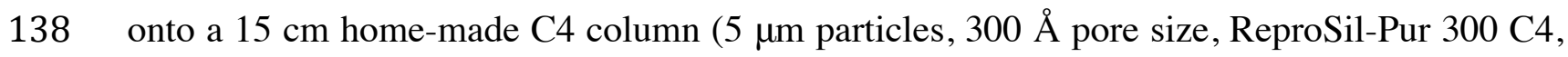

139 Dr. Maisch GmbH, Ammerbuch-Entringen, Germany) and eluted by a one step gradient from $1403.0 \%$ to $80 \%$ solvent $\mathrm{B}(80 \% \mathrm{ACN}, 0.1 \% \mathrm{FA})$ in $50 \mathrm{~min}$, at a flow rate of $250 \mathrm{~nL} / \mathrm{min}$. MS 141 data was acquired using Xcalibur software with a survey scan (100-1800 m/z) analyzed into 142 the Orbitrap mass analyzer at a resolution setting of 60,000 followed by 15 CID 143 fragmentations analyzed in the linear ion trap. The AGC* target for MS and MS/MS scans 144 were set to $1 \mathrm{E} 6$ and $5 \mathrm{E} 3$ respectively. The isolation width was set to $2.5 \mathrm{~m} / \mathrm{z}$ and the 145 normalized collision energy was set to 35 . Selected ions were dynamically excluded for 15 146 sec.

147 Data analysis. All raw data was analyzed using MaxQuant software version 1.5.1.2 148 (48) and the Andromeda search engine (49). Based on the protein expression system, data was 149 searched against the complete E. coli strain K12 UniProt database (4,331 proteins, 150 downloaded 2015-10-08), and CyaA protein sequence. The digestion mode was set to trypsin, 151 and a maximum of two missed cleavages were allowed. Carbamidomethylation of cysteine 
was specified as a fixed modification. Variable modifications considered were N-terminal acetylation, oxidation of methionines and N-acylation of lysines (Myristoyl-4H, 154 Myristoleylation, Myristoylation, Palmitoleylation, Palmitoylation). The minimum peptide 155 length was fixed to 5 amino acids and the required false discovery rate was set to $1 \%$ at the peptide spectrum match (PSM) and protein level. The main search peptide tolerance was set to $4.5 \mathrm{ppm}$ and to $0.5 \mathrm{Da}$ for the MS/MS match tolerance. Second peptides were enabled to identify co-fragmentation events. Results of PTM identification are shown in Supplemental Figures S2A-C.

\section{HDX-MS of pro-CyaA and CyaA conformation and dynamics}

We used Hydrogen/Deuterium eXchange followed by Mass Spectrometry (HDX-MS) to characterize the refolding process of pro-CyaA and CyaA equilibrated in 6,3 or $1.6 \mathrm{M}$ urea, as well as the monomeric species in the complete absence of denaturant. Two experimental conditions were analyzed; $A$ : to monitor the effect of post-translational acylation on the refolding process of full-length pro-CyaA and CyaA at $6 \mathrm{M}, 3 \mathrm{M}$ and $1.6 \mathrm{M}$ urea, and $B$ : to determine the effect of acylation on the full-length pro-CyaA and CyaA monomers. To achieve this, several proteins and conditions were analyzed; firstly, pro-CyaA and CyaA each in the presence of 6,3 and $1.6 \mathrm{M}$ urea containing either $2 \mathrm{mM} \mathrm{CaCl}_{2}$ or $2 \mathrm{mM}$ EDTA, and secondly, fully-folded pro-CyaA and CyaA monomers in buffer A, complemented with $2 \mathrm{mM}$ $\mathrm{CaCl}_{2}$.

$H D X-M S$ sample preparation. Prior to addition of the deuterated buffer $\left(100 \% \mathrm{D}_{2} \mathrm{O}\right.$ in $20 \mathrm{mM}$ Hepes, $150 \mathrm{mM} \mathrm{NaCl}$, pD 7.4, supplemented or not with $6 \mathrm{M}, 3 \mathrm{M}$ or $1.6 \mathrm{M}$ urea), all solutions were equilibrated for $1 \mathrm{~h}$ at $20^{\circ} \mathrm{C}$. For experiment A, labeling was initiated by diluting each sample five-fold with the deuterated buffer and incubated for $\mathrm{t}=0.16,1,10,60$, and $240 \mathrm{~min}$ at $20^{\circ} \mathrm{C}$ (final protein concentration of $0.3 \mu \mathrm{M}$ during labeling); experiment $\mathrm{B}$ was performed using a final protein concentration of $1 \mu \mathrm{M}$ and identical labeling conditions for $\mathrm{t}=0.16,0.5,1,5,10,30,60,120,240,480$ and $1440 \mathrm{~min}$, respectively.

The $80 \%$ excess of deuterium reached during labeling ensured unidirectional exchange. Aliquots of 3-10 pmol of protein were withdrawn at each experimental time point and quenched upon mixing of the deuterated sample with ice-cold $0.5 \%$ formic acid solution to achieve a final $\mathrm{pH}$ of 2.5. For experiment $\mathrm{A}$ (in the presence of urea), the quench was performed by mixing $14 \mathrm{~mL}$ of labeled sample with $56 \mathrm{~mL}$ of ice cold $0.5 \%$ formic acid (ratio 1/5: v/v, final $\mathrm{H}_{2} 0 / \mathrm{D}_{2} 0$ ratio $=20 \% / 80 \%$ )]. For experiment $\mathrm{B}$ (monomeric species), the quench was performed by mixing $30 \mathrm{~mL}$ of labeled sample with $30 \mathrm{~mL}$ of ice cold $0.5 \%$ formic acid (ratio $1 / 2$ : v/v, final $\mathrm{H}_{2} 0 / \mathrm{D}_{2} 0$ ratio $=50 \% / 50 \%$ )]. Quenched samples were immediately snapfrozen in liquid nitrogen and stored at $-80^{\circ} \mathrm{C}$ for approximately $12 \mathrm{~h}$. Undeuterated controls were treated using an identical procedure. Triplicate independent technical analyses were performed for each time point and condition for all HDX-MS analyses.

HDX-MS data acquisition. Prior to MS analysis, samples were rapidly thawed. To maintained at $0^{\circ} \mathrm{C}$. To achieve this, local HDX analyses were performed with the aid of a 
cooled HDX Manager (Waters Corporation, Milford, MA). Samples were digested using an in-house prepared cartridge of immobilized pepsin beads (Thermo Scientific, Rockford, IL),

194 for $2 \mathrm{~min}$ at $70 \mu \mathrm{L} / \mathrm{min}$ and $20^{\circ} \mathrm{C}$. Peptic peptides were rapidly desalted and concentrated using a Vanguard C18 pre-column $(1.7 \mu \mathrm{m}, 2.1$ x $5 \mathrm{~mm}$; Waters Corporation), and separated using an ACQUITY UPLC ${ }^{\text {Tм }}$ BEH C18 column $(1.7 \mu \mathrm{m}, 1$ x $100 \mathrm{~mm})$. Pro-CyaA and CyaA peptides were separated over a 10 min gradient of $5-40 \% \mathrm{ACN}$ at $38 \mu \mathrm{L} / \mathrm{min}$ and at $0^{\circ} \mathrm{C}$. The LC flow was directed to a Synapt ${ }^{\mathrm{TM}}$ G2-Si HDMS ${ }^{\mathrm{TM}}$ mass spectrometer (Waters), which was equipped with ESI and lock-mass correction using Glu-Fibrinogen peptide. Mass spectra were acquired in positive-ion mode over the $\mathrm{m} / \mathrm{z}$ range of 50-1800 using a data-independent acquisition scheme (MS ${ }^{\mathrm{E}}$ ) whereby exact mass information is collected at both low and high collisional energies for collisional induced dissociation. Unlabeled pro-CyaA and CyaA samples were digested in triplicate to build a peptide coverage map.

HDX-MS data processing. Peptide identification was via the Protein Lynx Global Server (PLGS) 3.0 (Waters Corporation). Oxidation of methionines and carbamylation of Nterminal and lysine residues were set as variable modifications. The sequence coverage map (Supplemental Figures S3 and S4) was plotted using DynamX 3.0 HDX software (Waters). For the native proteins, pepsin digestion yielded 232 unique peptides identified from their accurate masses and product ion spectra. A total of 141 peptides were brought forward for HDX data analysis, corresponding to a sequence coverage of $91.0 \%$. For the proteins in urea, 172 peptides, covering $85.7 \%$ of the protein sequence, were selected for final analysis. The reduced sequence coverage witnessed here was due to the experimental design necessitating a lower protein load on column at the $1.6 \mathrm{M}$ urea concentration (down to $3 \mathrm{pmol}$, in contrast to $10 \mathrm{pmol}$ for all other states), resulting in a knock-on decrease in MS sensitivity. $\mathrm{D}_{2} \mathrm{O}$ uptake at the peptide level was extracted and visualized in uptake charts, difference plots, and heat maps, performed in both DynamX and MEMHDX (50). Statistical analysis of HDX-MS results was performed with MEMHDX (Wald test, false discovery rate sets to $1 \%$ ).

\section{Urea unfolding of pro-CyaA and CyaA monomers}

A volume of $2.5 \mu \mathrm{L}$ of CyaA or pro-CyaA monomers stored in $20 \mathrm{mM}$ Hepes, 150 $\mathrm{mM} \mathrm{NaCl}, 2 \mathrm{mM} \mathrm{CaCl}_{2}$, pH 7.5 was diluted in $20 \mathrm{mM}$ Hepes, $150 \mathrm{mM} \mathrm{NaCl}, 2 \mathrm{mM} \mathrm{CaCl}$, containing urea at various concentrations to obtain a final concentration of toxin of $50 \mathrm{nM}$. A total of 22 tubes were prepared, with a urea gradient from 0 to $6 \mathrm{M}$. Once diluted, the toxin was incubated at room temperature for $1 \mathrm{~h}$. Emission spectra of the protein were acquired on a Jasco FP 8200 spectrofluorimeter (Jasco, Tokyo, Japan) using a 3 x $3 \mathrm{~mm}$ path length quartz cell (105.251.QS, Hellma Analytics). The excitation wavelength was set to $280 \mathrm{~nm}$, both emission and excitation slits were fixed at $5 \mathrm{~nm}$, and fluorescence emission spectra were recorded from 300 to $400 \mathrm{~nm}$. Spectra were acquired at $25^{\circ} \mathrm{C}$. The ratio of fluorescence intensities at 340 and $380 \mathrm{~nm}$ were plotted against the urea concentration.

Freshly prepared ANS was added to pro-CyaA or CyaA monomers to reach final 
concentrations of 5 and $0.5 \mu \mathrm{M}$, respectively (molar ratio of ANS:toxin was 10:1). Excitation was fixed at $360 \mathrm{~nm}$ and emission spectra were recorded between 400 and $600 \mathrm{~nm}$ on a Jasco FP 8200 spectrofluorimeter (Jasco, Tokyo, Japan) using either a 3 x $3 \mathrm{~mm}$ path length quartz cell (105.251.QS, Hellma Analytics) or a $10 \mu \mathrm{L}$ drop cell. All spectra were acquired at $25^{\circ} \mathrm{C}$. Analytical ultracentrifugation (AUC) analysis of pro-CyaA and CyaA monomers

Sedimentation velocity experiments were performed on a Beckman XL-A analytical ultracentrifuge (Beckman Coulter) in a AN60-Ti rotor at $20^{\circ} \mathrm{C}$. All samples were filtered on $0.2 \mu \mathrm{m}$ filters before experiments. Detection of the protein concentration as a function of radial position and time was performed by optical density measurements at a wavelength of $280 \mathrm{~nm}$. For sample analysis, $400 \mu \mathrm{L}$ of pro-CyaA or CyaA at $1 \mu \mathrm{M}$ was loaded into a 1.2 mm-thick two-channel epoxy centerpiece and spun at 20,000 rpm. Data were analyzed with SEDFIT software using a continuous size distribution $\mathrm{c}(\mathrm{s})$ model $(15,41,51)$. Hemolysis of erythrocytes

The hemolytic activity of pro-CyaA and CyaA was determined on sheep erythrocytes as previously described (47). Briefly, sheep erythrocytes were washed several times with buffer $\mathrm{A}$ and resuspended at $5 \times 10^{\mathrm{s}}$ cells $/ \mathrm{mL}$. The hemolytic activity of pro-CyaA and CyaA was measured after overnight incubation of erythrocytes at $37^{\circ} \mathrm{C}$ by quantifying the amount of hemoglobin released at $540 \mathrm{~nm}$ (and of intracellular content release at $405 \mathrm{~nm}$ ).

\section{Pro-CyaA and CyaA translocation and cAMP production in erythrocytes}

The invasive activity of CyaA was determined by measuring the intracellular cAMP accumulation as previously described (47). Briefly, erythrocyte suspensions $\left(5 \times 10^{8}\right.$ cells $/ \mathrm{mL}$ in buffer A) were incubated with $5.6 \mathrm{nM} \mathrm{CyaA}\left(1 \mu \mathrm{g} \cdot \mathrm{mL}^{-1}\right)$ at $37{ }^{\circ} \mathrm{C}$ for $20 \mathrm{~min}$. The cells were washed and lyzed as described (41) and then the intracellular cAMP content was determined by a homemade competitive ELISA immunoassay (52) using a rabbit anti-cAMP antiserum (1818-II) and a goat anti-rabbit IgG coupled to alkaline phosphatase (Sigma, Life Science). The alkaline phosphatase activities were revealed with 4-Nitrophenyl phosphate disodium salt hexahydrate (PA substrate from Sigma, Life Science) and cAMP concentrations were calculated from a standard curve established with known concentrations of cAMP diluted in buffer $\mathrm{A}$.

\section{Data availability}

261 All data generated and analyzed during this study are included in this published article and its

262 supplemental information files. 


\section{Production and MS characterization of CyaA and pro-CyaA}

Pro-CyaA and CyaA were overexpressed in E. coli - the latter by co-expression of proCyaA and CyaC (53-55) - and purified to homogeneity using established methods (47). To identify the acyl chains incorporated in CyaA, the pro-CyaA and CyaA proteins were digested by Lys-C and trypsin and analyzed by MS. Two peptides (858-872 and 972-984) containing the K860 and K983 residues were identified. Both residues were primarily palmitoleylated (C16:1) in CyaA (see Supplemental Figures S1A-C). Palmitoylation (C16:0) was also identified on both K860 and K983 residues. Traces of myristoylation (C14:0) were observed on K983. As expected, no acylation was detected on K860 or K983 in pro-CyaA. In summary, CyaA is primarily post-translationally modified with C16 acyl chains on both lysines, while pro-CyaA is devoid of the PTM.

\section{Refolding and functional activities of CyaA and pro-CyaA}

Due to their size and hydrophobic character, both pro-CyaA and CyaA proteins are prone to aggregation. They are traditionally purified in the presence of chaotropic agents (usually urea) and stored in an unfolded state in denaturing conditions (i.e., 6-8 $\mathrm{M}$ urea). Upon refolding by urea dilution, mixtures of multimeric and monomeric species are commonly obtained, precluding further biochemical and biophysical characterization (41). Yet, we have recently achieved to refold both pro-CyaA and CyaA into monomeric states (see Supplemental Figure S2) that remain stable in the absence of urea $(41,47)$, thus allowing us to investigate the relationship between the structure and function of these two species. The method is based on molecular confinement to prevent intermolecular interactions between hydrophobic regions of proteins upon their refolding. Refolding is performed on a sizeexclusion chromatography column used as molecular confinement media comprising a matrix characterized by small size particles (see methods for details and Supplemental Figure S2). In addition to the monomeric species, this refolding procedure also leads to the formation of a heterogeneous population of CyaA multimers. We have previously observed that beside molecular confinement, refolding is critically dependent on the presence of calcium and toxin acylation $(41,47)$. However, we succeeded to refold pro-CyaA into a monomeric protein by optimizing the procedure, essentially by decreasing the initial protein concentration, although the recovery yield was low as compared to that of acylated CyaA (see Supplemental Figure S2 and methods for details).

The biological activities of the refolded pro-CyaA and CyaA species were assessed on sheep erythrocytes by monitoring hemolytic activity and the ability of the toxins to invade cells (Supplemental Table S1). As expected, the monomeric CyaA species induced hemolysis and was able to bind to erythrocytes and translocate into the cytosol in a calcium-dependent manner, in agreement with prior studies $(25,47,55,56)$. In contrast, the multimeric CyaA species exhibited strongly reduced hemolytic activity and was not able to translocate into erythrocytes while the pro-CyaA species were totally lacking hemolytic and cell invasion capacities (Supplemental Table S1) in agreement with previous studies $(53,57)$. This 
confirms that the monomeric, acylated CyaA is the physiological competent state of the toxin, able to invade eukaryotic target cells.

\section{Compactness and solvent-exposed hydrophobic regions in CyaA and pro-CyaA}

We then characterized the biophysical and hydrodynamic properties of pro-CyaA and

CyaA. We first determined the compactness and stability of both proteins using macroscopic approaches, and then characterized the proteins at medium resolution by HDX-MS. The solvent-exposed hydrophobic surfaces of pro-CyaA and CyaA monomers were probed using ANS fluorescence (58) in buffer A, complemented with $2 \mathrm{mM} \mathrm{CaCl}_{2}$. While a slight increase in ANS fluorescence intensity was observed in the presence of CyaA monomers, a marked increase (approximately 3-fold) was found with the pro-CyaA monomers, suggesting that these latter expose more hydrophobic regions to the solvent than the former (Figure 2A). In other words, the hydrophobic regions in CyaA monomers are less accessible to ANS than those in the pro-CyaA species, suggesting that acylation favors the shielding of hydrophobic regions within the protein. We then investigated the compaction state of CyaA and pro-CyaA by sedimentation velocity analysis using AUC. Both species remain essentially monomeric, with only a few aggregates observed on the time scale of the experiment (Figure 2B). The analysis provided a sedimentation coefficient of 7.4 and $7.1 \mathrm{~S}$, respectively, for CyaA and pro-CyaA monomers (Figure 2B and Supplemental Table S2), suggesting that pro-CyaA monomers are slightly less compact than CyaA monomers. We further compared the stability of pro-CyaA and CyaA monomers by following their urea induced unfolding by intrinsic tryptophan fluorescence. The denaturation data also indicate that CyaA is more stable than pro-CyaA at urea concentrations above $2 \mathrm{M}$ (Figure $2 \mathrm{C}$ ) as highlighted by the plot of the maximum wavelength differences between the two proteins (Figure 2D). Taken together, these results indicate that pro-CyaA monomers expose more hydrophobic regions to the solvent (Figure 2A), and are less compact (Figure 2B) and stable (Figures 2C-D) than CyaA monomers.

\section{HDX-MS analysis of the pro-CyaA and CyaA refolding process}

To further characterize the refolding process of pro-CyaA and CyaA, we used HDXMS to probe the structure and dynamics of both full-length proteins equilibrated in 6,3 or 1.6 $\mathrm{M}$ urea, as well as the monomeric species in the complete absence of denaturant. Figure 3 displays a global view of the relative deuterium fractional uptake of CyaA equilibrated in 6,3 or $1.6 \mathrm{M}$ urea in the presence of $2 \mathrm{mM} \mathrm{CaCl}_{2}$. The relative fractional exchanges of three independent replicates were calculated for each peptide at each time point and plotted as a function of peptide position (CyaA peptide maps are shown in figures S3 and S4). In $6 \mathrm{M}$ urea (Figure 3B), the protein is totally devoid of dynamic HDX-MS events, confirming that CyaA is completely denatured. In $3 \mathrm{M}$ urea (Figure 3C), a short segment of the hydrophobic region (658-719 in HR) and a large part of the RTX domain (RD, from Block II to the C-terminal extremity of CyaA) exhibit dynamic HDX-MS behavior, while in 1.6 M urea (Figure 3D), part of the catalytic domain (the T25 region of AC), AR and most of HR also has dynamic 
structural elements upon progressive urea removal. This sequential folding of CyaA is further highlighted in Supplemental Figure S5. To identify the contributions of calcium on CyaA refolding, similar HDX-MS experiments were repeated in the absence of calcium (Supplemental Figure S6). In these conditions, the entire CyaA polypeptide remains solvent accessible and unfolded at all urea concentrations, even down to 1.6 M. The uptake difference plots between CyaA samples in the presence of calcium or EDTA at various urea concentrations are compared in Figure 4 (and Supplemental Figures S7-S9 for a detailed presentation of the HDX-MS data). These HDX-MS results show that the presence of calcium is critical for the acquisition of structural elements in CyaA at $3 \mathrm{M}$ and 1.6 $\mathrm{M}$ urea. This further indicates that calcium binding to the RTX motifs is critical not only to induce folding of the C-terminal RD domain (see the effect of calcium versus EDTA at $3 \mathrm{M}$ urea in Figure 4C), but also for the structuration of all of the upstream N-terminal domains of CyaA (see the effect of calcium versus EDTA at 1.6 M urea in Figure 4D).

Similar HDX-MS experiments were also performed on pro-CyaA (Supplemental Figure S10) and revealed a comparable sequential refolding process with RD acquiring structures at intermediate urea concentrations $(3 \mathrm{M})$, followed by the refolding of $\mathrm{AC}$ and $\mathrm{HR}$ regions at lower urea concentrations (1.6 M) (Supplemental Figures S10 and S11). As in CyaA, several regions of pro-CyaA display non-dynamic HDX-MS throughout, indicating that these regions remain largely unstructured, even at low urea concentrations. These include a large stretch of amino acids from the C-terminal end of the catalytic domain (T18 fragment), across the translocation region, TR, and through the N-terminal part of HR, i.e., from residues 345 to 570 . Similarly, residues 821 through 981 of the AR domain show non-dynamic HDXMS behavior throughout. Significant differences do exist between the acylated and nonacylated proteins, however, as illustrated in Figure 5, which shows the difference in deuterium uptake between pro-CyaA and CyaA at both $3 \mathrm{M}$ and $1.6 \mathrm{M}$ urea. In $3 \mathrm{M}$ urea (Figure 5B), the differences are confined to a segment of the HR between amino acids 658 and 719. In 1.6 $\mathrm{M}$ urea (Figure 5C), further minor structural disparities between pro-CyaA and CyaA are evidenced, extending upstream from the HR to the TR region, through to the $\mathrm{N}$-terminal part of $\mathrm{AC}$, and, conversely, downstream, to the $\mathrm{AR}$ region. It therefore seems that the acyl chains at K860 and K983 of CyaA are critically involved in the folding of the segment encompassing residues 658 to 719 (Figures 5B-C). We propose that the hydrophobic effects between the acyl chains and HR restrict the conformational landscape of CyaA, thus favoring a faster refolding towards the folded state, as compared to pro-CyaA. The present data suggests that the segment covering residues circa 660-710 of the HR can act as a hydrophobic folding nucleus, even in the presence of $3 \mathrm{M}$ urea if K860 and K983 are acylated (Figures 3 and 5C). In pro-CyaA, this hydrophobic collapse occur at lower urea concentrations due to the lack of acyl chains (Figure S11), and consequently, the partially folded hydrophobic regions may remain exposed to the solvent, thereby favoring the aggregation of pro-CyaA into multimeric species. 
The relative fractional uptake maps of monomeric pro-CyaA and CyaA species (both in the absence of urea) are displayed in Figure 6. Extensive dynamic HDX-MS activity, indicative of secondary structural elements, is observed throughout both proteins. Yet, segments that connect individual sub-domains, such as at the boundary of the AC/TR, HR/AR, and $\mathrm{AR} / \mathrm{RD}$ domains, appear to be more accessible than the adjacent domains. Equivalent HDX-MS patterns are observed between several domains of pro-CyaA and CyaA monomers as illustrated in the uptake difference plot (Figure 6D), in particular the N-terminal parts of both AC and TR, and the blocks III to V of RD. These data suggest that the folding of these regions is not affected by CyaA acylation. The C-terminal part of TR (circa 454-520) and the $\mathrm{N}$-terminal part of RD (mainly blocks I and II) are weakly but significantly stabilized by the presence of the acyl chains (Figure 6D).

The strongest differences in HDX-MS activity between the two forms of CyaA are found in the hydrophobic and acylation regions (Figures 6D-E). Firstly, peptides from the AR region (i.e. residues between amino acids 798 and 958), appear to be more solvent accessible in pro-CyaA monomer than in the monomeric CyaA toxin (Figures $6 \mathrm{~B}$ and 6C, respectively). Secondly, significant changes in HDX-MS patterns are observed in the hydrophobic region of CyaA, most notably at peptides 539-546, 571-582, 615-622, 658-672, 682-696 and 686-696 (highlighted in Figures 6D, 6E and S12), corresponding to the four hydrophobic segments of HR (Supplemental Figures S12 and S13). Interestingly, a significant difference in HDX-MS activity is observed in all experimental conditions between pro-CyaA and CyaA for the hydrophobic segment between amino acids 660 and 710 (Figures 5B-C, 6 and S13). This confirms that these hydrophobic segments may indeed play an essential role in the folding process of the acylated toxin, from the initial structural elements observed at $3 \mathrm{M}$ urea (Figures 3 and 5) to the native state of the monomeric CyaA (Figure 6). The HDX-MS data provides direct evidence that CyaA acylation favors a hydrophobic collapse of these regions that may constitute the apolar core of the protein structure.

\section{DISCUSSION}

Acylation is a requisite PTM for the cytotoxicity of RTX toxins, but the precise contribution of acyl chains to the structure and function of these cytolysins still remains largely unknown. We previously suggested that acylation may play a crucial role in the refolding of the $B$. pertussis adenylate cyclase toxin, CyaA, a prominent member of the RTX toxin family, into a monomeric and functional species $(41,47)$. To gain further insights into the effect of CyaA acylation, we directly compared the biophysical and functional properties of the monomeric acylated and non-acylated forms (CyaA and pro-CyaA, respectively) of this toxin.

MS analysis indicates that CyaA produced in E. coli in the presence of the CyaC acyltransferase is mainly modified by $\mathrm{C} 16$ acyl chains on $\mathrm{K} 860$ and $\mathrm{K} 983$, and, as expected, pro-CyaA is not. AUC experiments demonstrate that CyaA monomers are more compact than their pro-CyaA counterparts, while ANS binding studies show that hydrophobic regions are 
less solvent-exposed in CyaA than in pro-CyaA. This indicates that the presence of acyl chains in CyaA may favor a more compact structural state. Furthermore, urea-induced unfolding experiments suggest that the acylated toxin is more stable than pro-CyaA. All together, our AUC and fluorescence data shows that several hydrophobic regions may be more solvent-exposed in pro-CyaA than CyaA, leading to a less compact and stable protein.

We exploited HDX-MS to unravel the folding process of both pro-CyaA and CyaA by analyzing their structural dynamics at different urea concentrations. These studies lead to two important conclusions. Firstly, we show that in both forms of the protein, i.e., independently of the acylation-status, the C-terminal RTX-containing domain RD is the first region to acquire structure when the refolding is carried out in the presence of calcium (Figures 3, 4 and S5-11). More importantly, we found that in the absence of calcium the entire protein remains essentially unstructured even after lowering urea concentrations down to $1.6 \mathrm{M}$ urea, as indicated by the absence of any significant solvent-protection across the entire CyaA polypeptide chain (Figures S6-S9 and 4D). In marked contrast, in the presence of calcium, most CyaA domains do contain structural elements at $1.6 \mathrm{M}$ urea and in the absence of urea, as evidenced by HDX-MS (Figures 3D, 4D, 6C, S5A and S9). Our previous studies already established that the RTX domain of CyaA, RD, (residues 1006-1706) is intrinsically disordered in the calcium-free apo-state and folded in the calcium-bound holo-state (4, 31-39, $41,42,59)$. A likely scenario is that, in the absence of calcium, the intrinsically disordered nature of RD within the full-length protein may result in a huge entropic penalty that prevents folding of the other CyaA domains. This data has direct implications for CyaA secretion. We previously suggested that in the low calcium environment of the bacterial cytosol, RD adopts disordered conformations favorable for transport through the type 1 secretion machinery, and folds upon binding calcium in the extracellular, calcium-rich environment $(4,32,34,39,41$, 42). Our present data now extends this model to the full-length CyaA toxin. Indeed, our HDX-MS results clearly indicate that in the low calcium environment of the bacterial cytoplasm, it is not only the RD domain, but the CyaA polypeptide chain as a whole, that preferentially adopts unstructured conformations that fosters protein secretion through the type 1 secretion channel. Upon secretion, as the protein reaches the calcium-rich extracellular medium, RD binds calcium, folds, and may then act as a scaffold for the refolding of the upstream domains of CyaA that are progressively exiting the T1SS machinery in a C- to- $\mathrm{N}$ terminal vectorial secretion process (39-41).

The second major finding of this study is that acylation plays a critical role in the folding of CyaA into a functional cytotoxic state. HDX-MS revealed dramatic differences in deuterium uptake between the acylated and non-acylated CyaA, mainly located in the hydrophobic and acylation regions (Figures 5, 6, S5, S11 and S12). More specifically, we identified a segment (circa residues 660-710) within the hydrophobic region and distal from the acylation sites, which appears to play a central role in toxin refolding (Figures 5B-C). We propose that in CyaA, this region may directly interact and collapse with the distant acyl chains, in a process driven by hydrophobic effects. The formation of these structural elements 
463 may orient the initial CyaA folding pathway and favor toxin refolding into the monomeric 464 state. In contrast, pro-CyaA may have to explore a broader conformational landscape due to 465 the absence of the initial hydrophobic collapse between residues 660-710 and the acyl chains.

466 Thus, from a kinetic point of view, the acyl chains may favor a faster folding of CyaA as 467 compared to pro-CyaA. This could also explain the higher propensity of pro-CyaA to 468 aggregate, and consequently the lower yield of pro-CyaA monomers compared to CyaA 469 during the refolding process (Supplemental Figure S2).

470 We propose the following calcium- and acylation-dependent refolding scheme for 471 CyaA: as CyaA exits from the T1SS, calcium-binding triggers refolding of the C-terminal 472 RTX domain. As previously proposed, the calcium-loaded, folded RTX domain might act as a 473 scaffold for the folding of other CyaA domains, i.e., AR and HR (Figures 3, 4 and S7-S9).

474 The acyl chains attached to K860 and K983 foster a hydrophobic collapse within the apolar 475 segment spanning residues 660-710 (Figures 5 and S13), which acts as a nucleus for the 476 folding into the native state (Figure 6D) of both HR (residues 528-710) and AR (711-1005). 477 Finally, TR and AC are secreted and, interestingly, their folding appears minimally affected 478 by the acylation status. This is in agreement with the fact that the isolated AC and AC-TR 479 polypeptides can autonomously fold in solution $(15,16,24)$. Taken together, the calcium480 induced folding, coupled with hydrophobic effects between distal regions containing apolar 481 segments and acyl chains, is likely shared with other multi-domain proteins. This is probably 482 the case of other large RTX cytolysins like CyaA, which are secreted in an unfolded state and 483 refold in the host environment to exert their virulence $(3,4)$. 
486 D.O.B was supported by PasteurInnov2015-197 and PTR451 grants. S.E.C. was supported by 487 a stipend from the Pasteur - Paris University (PPU) International PhD Program. A.V. was 488 supported by a DIM MalInf (infectious diseases) grant. We thank Bertrand Raynal and 489 Sébastien Brulé from the PFBMI for their excellent technical expertise with AUC. Running 490 costs were supported by Institut Pasteur, PasteurInnov (PIV15-197), PTR grant (PTR451), 491 CNRS, Fondation Recherche Médicale (FRM DBS20140930771). We thank the CACSICE 492 Equipex ANR-11-EQPX-0008.

493

\section{AUTHOR CONTRIBUTIONS}

495 A.C. designed the project. D.O.B., T.D., M.M., S.B., and A.C. designed the experiments. 496 D.O.B., S.E.C., A.V., M.D., T.D., S.B., and A.C. performed the experiments. D.O.B., S.E.C., 497 T.D., M.M., S.B., D.L. and A.C. analyzed the data. D.O.B., S.E.C., S.B., D.L., and A.C. 498 wrote the manuscript. All authors discussed the results and commented on the manuscript. 499

\section{DECLARATION OF INTERESTS}

501 The authors declare no competing interests.

502

\section{SUPPLEMENTAL INFORMATION}

504 The Supplemental Information file contains 13 Supplemental Figures and 2 Supplemental 505 Tables. 
Figure 1: Schematic representation of the multi-domain CyaA toxin (1706 amino acid residues). The toxin contains the following domains: a N-terminal adenylate cyclase catalytic domain (AC, residues 1-364), a translocation region (TR, residues 365-527), a hydrophobic region (HR, residues 528 to 710), an acylation region (AR, residues 711-1005 with acylated Lys 860 and Lys 983 marked with yellow stars), and a C-terminal RTX domain (RD, 10061706), composed of five consecutive blocks.

Figure 2: Macroscopic characterization of $\mathrm{CyaA}$ and pro-CyaA monomeric species. Panel A shows the emission fluorescence spectra of ANS in the absence (black) and in the presence of CyaA (blue) and pro-CyaA (red) monomers. Panel B shows the distribution of sedimentation coefficients c(s) of CyaA (blue) and pro-CyaA (red) monomers measured by analytical ultracentrifugation (AUC). The AUC data are presented in Supplemental Table S2. Panel $\mathrm{C}$ shows the urea-induced unfolding of CyaA (blue) and pro-CyaA (red) monomers followed by tryptophan fluorescence (s.d.: $\pm 1 \mathrm{~nm}$ ). The variation of maximum wavelength emission (lmax) between CyaA and pro-CyaA is highlighted in panel D. Buffer: buffer A, complemented with $2 \mathrm{mM} \mathrm{CaCl}_{2}$. These experiments were performed in triplicate.

Figure 3: HDX-MS analysis of CyaA refolding. The structural organization of each domain is displayed in Panel A and fits to the peptide maps shown in panels B, C and D. The 5 blocks of RD are sized to fit to the peptide maps shown in panels $B, C$ and D. The HDX-MS behavior of CyaA in various concentrations of urea and in the presence of $2 \mathrm{mM}$ calcium is displayed in Panels B to D. At $6 \mathrm{M}$ urea (B), no dynamic HDX-MS behavior is observed throughout the protein. At $3 \mathrm{M}$ urea (C), only RD and a small section of HR display dynamic activity. At 1.6 M urea (D), the AC, HR and RD domains exhibit dynamic HDX-MS events. Each dot corresponds to the average value of three independent replicates.

Figure 4: Deuterium uptake differences of $\mathrm{CyaA}$ in urea in the presence and absence of calcium. The structural organization of each domain is displayed in Panel A and fits to the peptide maps shown in panels B, C and D. The fractional uptake difference plots were calculated at each urea concentration by subtracting the uptake measured in the absence ( 2 mM EDTA) and the presence of calcium $\left(2 \mathrm{mM} \mathrm{CaCl}_{2}\right)$ for each peptide and at each time point (Panels B-D). At $6 \mathrm{M}$ urea, no difference of HDX-MS behavior is observed throughout the protein. At $3 \mathrm{M}$ urea $(\mathrm{C})$, only RD displays significant positive difference of deuterium uptake, indicative of a calcium-induced reduction of solvent accessibility, i.e., protein folding in the presence of calcium. At 1.6 M urea (D), the AC, AR and RD domains show a positive difference of deuterium uptake, indicating that the presence of calcium induces the folding of these domains. Each dot corresponds to the average value of three independent replicates. 
548 presence of calcium at 3 and 1.6 $\mathrm{M}$ urea. The structural organization of each domain is

549 displayed in Panel A and fits to the peptide maps shown in panels B and C. Panels B-C

550 display the uptake difference plot between pro-CyaA and CyaA proteins at $3 \mathrm{M}$ and $1.6 \mathrm{M}$

551 urea concentrations, respectively. Only a difference in HR was observed (highlighted in red

552 boxes). Each dot corresponds to the average value of three independent replicates. Panel C

553 shows peptides from HR with the greatest deuterium uptake differences between the two

554 proteins. Errors bars (SD) are within the size of the dots.

555

556 Figure 6: HDX-MS analysis of monomeric pro-CyaA and CyaA species in solution. The

557 structural organization of each domain is displayed in Panel A and fits to the peptide maps

558 shown in panels B, C and D. The HDX-MS behaviors of full-length pro-CyaA and CyaA

559 monomers measured in the presence of $2 \mathrm{mM}$ calcium are given in Panels $\mathrm{B}$ and $\mathrm{C}$. Dynamic

560 HDX-MS are observed throughout both proteins and over the time course of the reaction. The

561 uptake difference plot between both pro-CyaA and CyaA monomers is shown in Panel D.

562 Large differences in HDX-MS activity between the two proteins were observed in HR and

563 AR (red boxes). Smaller changes were found in T18, TR and Blocks I and II of RD. Each dot

564 corresponds to the average value of three independent replicates. Panel E shows selected

565 peptides from HR and AR. Errors bars (SD) are within the size of the dots. 


\section{REFERENCES}

1. Siman, P., and Brik, A. (2012) Chemical and semisynthesis of posttranslationally 
19. Glaser, P., Sakamoto, H., Bellalou, J., Ullmann, A., and Danchin, A. (1988) Secretion of cyclolysin, the calmodulin-sensitive adenylate cyclase-haemolysin bifunctional protein of Bordetella pertussis. Embo J 7, 3997-4004

20. Bellalou, J., Sakamoto, H., Ladant, D., Geoffroy, C., and Ullmann, A. (1990) Deletions affecting hemolytic and toxin activities of Bordetella pertussis adenylate cyclase. Infection and immunity 58, 3242-3247

21. Bellalou, J., Ladant, D., and Sakamoto, H. (1990) Synthesis and secretion of Bordetella pertussis adenylate cyclase as a 200-kilodalton protein. Infection and immunity 58, 1195-1200

22. Sakamoto, H., Bellalou, J., Sebo, P., and Ladant, D. (1992) Bordetella pertussis adenylate cyclase toxin. Structural and functional independence of the catalytic and hemolytic activities. J Biol Chem 267, 13598-13602

23. Martin, C., Requero, M. A., Masin, J., Konopasek, I., Goni, F. M., Sebo, P., and Ostolaza, H. (2004) Membrane restructuring by Bordetella pertussis adenylate cyclase toxin, a member of the RTX toxin family.J Bacteriol 186, 3760-3765

24. Karst, J. C., Barker, R., Devi, U., Swann, M. J., Davi, M., Roser, S. J., Ladant, D., and Chenal, A. (2012) Identification of a region that assists membrane insertion and translocation of the catalytic domain of Bordetella pertussis CyaA toxin. J Biol Chem 287, 9200-9212

25. Masin, J., Osickova, A., Sukova, A., Fiser, R., Halada, P., Bumba, L., Linhartova, I., Osicka, R., and Sebo, P. (2016) Negatively charged residues of the segment linking the enzyme and cytolysin moieties restrict the membrane-permeabilizing capacity of adenylate cyclase toxin. Sci Rep 6, 29137

26. Subrini, O., Sotomayor-Perez, A. C., Hessel, A., Spiaczka-Karst, J., Selwa, E., Sapay, N., Veneziano, R., Pansieri, J., Chopineau, J., Ladant, D., and Chenal, A. (2013) Characterization of a membrane-active peptide from the Bordetella pertussis CyaA toxin. J Biol Chem 288, 32585-32598

27. Voegele, A., Subrini, O., Sapay, N., Ladant, D., and Chenal, A. (2017) MembraneActive Properties of an Amphitropic Peptide from the CyaA Toxin Translocation Region. Toxins (Basel) 9

28. Barry, E. M., Weiss, A. A., Ehrmann, I. E., Gray, M. C., Hewlett, E. L., and Goodwin, M. S. (1991) Bordetella pertussis adenylate cyclase toxin and hemolytic activities require a second gene, cyaC, for activation.J Bacteriol 173, 720-726

29. Masin, J., Basler, M., Knapp, O., El-Azami-El-Idrissi, M., Maier, E., Konopasek, I., Benz, R., Leclerc, C., and Sebo, P. (2005) Acylation of lysine 860 allows tight binding and cytotoxicity of Bordetella adenylate cyclase on CD11b-expressing cells. Biochemistry 44, 12759-12766

30. Bouchez, V., Douche, T., Dazas, M., Delaplane, S., Matondo, M., Chamot-Rooke, J., and Guiso, N. (2017) Characterization of Post-Translational Modifications and Cytotoxic Properties of the Adenylate-Cyclase Hemolysin Produced by Various Bordetella pertussis and Bordetella parapertussis Isolates. Toxins (Basel) 9

31. Bauche, C., Chenal, A., Knapp, O., Bodenreider, C., Benz, R., Chaffotte, A., and Ladant, D. (2006) Structural and functional characterization of an essential RTX subdomain of Bordetella pertussis adenylate cyclase toxin. J Biol Chem 281, 16914-16926

32. Chenal, A., Guijarro, J. I., Raynal, B., Delepierre, M., and Ladant, D. (2009) RTX calcium binding motifs are intrinsically disordered in the absence of calcium: implication for protein secretion. J Biol Chem 284, 1781-1789

33. Sotomayor Perez, A. C., Karst, J. C., Davi, M., Guijarro, J. I., Ladant, D., and Chenal, A. (2010) Characterization of the regions involved in the calcium-induced folding of 
41. Cannella, S. E., Ntsogo Enguene, V. Y., Davi, M., Malosse, C., Sotomayor Perez, A. C., Chamot-Rooke, J., Vachette, P., Durand, D., Ladant, D., and Chenal, A. (2017) Stability, structural and functional properties of a monomeric, calcium-loaded adenylate cyclase toxin, CyaA, from Bordetella pertussis. Sci Rep 7, 42065

42. O'Brien, D. P., Perez, A. C. S., Karst, J., Cannella, S. E., Enguene, V. Y. N., Hessel, A., Raoux-Barbot, D., Voegele, A., Subrini, O., Davi, M., Guijarro, J. I., Raynal, B., Baron, B., England, P., Hernandez, B., Ghomi, M., Hourdel, V., Malosse, C., Chamot-Rooke, J., Vachette, P., Durand, D., Brier, S., Ladant, D., and Chenal, A. (2018) Calciumdependent disorder-to-order transitions are central to the secretion and folding of the CyaA toxin of Bordetella pertussis, the causative agent of whooping cough. Toxicon : official journal of the International Society on Toxinology 149, 37-44

43. Rose, T., Sebo, P., Bellalou, J., and Ladant, D. (1995) Interaction of calcium with Bordetella pertussis adenylate cyclase toxin. Characterization of multiple calcium-binding sites and calcium-induced conformational changes. J Biol Chem 270, 26370-26376

44. Welch, R. A. (2001) RTX toxin structure and function: a story of numerous anomalies and few analogies in toxin biology. Current topics in microbiology and immunology 257, 85-111

45. Veneziano, R., Rossi, C., Chenal, A., Devoisselle, J. M., Ladant, D., and Chopineau, J. (2013) Bordetella pertussis adenylate cyclase toxin translocation across a tethered lipid bilayer. Proc Natl Acad Sci U S A 110, 20473-20478

46. Novak, J., Cerny, O., Osickova, A., Linhartova, I., Masin, J., Bumba, L., Sebo, P., and Osicka, R. (2017) Structure-Function Relationships Underlying the Capacity of Bordetella Adenylate Cyclase Toxin to Disarm Host Phagocytes. Toxins (Basel) 9 
47. Karst, J. C., Ntsogo Enguene, V. Y., Cannella, S. E., Subrini, O., Hessel, A., Debard, S., Ladant, D., and Chenal, A. (2014) Calcium, Acylation, and Molecular Confinement Favor Folding of Bordetella pertussis Adenylate Cyclase CyaA Toxin into a Monomeric and Cytotoxic Form. J Biol Chem 289, 30702-30716

48. Cox, J., and Mann, M. (2008) MaxQuant enables high peptide identification rates, individualized p.p.b.-range mass accuracies and proteome-wide protein quantification. Nature biotechnology 26, 1367-1372

49. Cox, J., Neuhauser, N., Michalski, A., Scheltema, R. A., Olsen, J. V., and Mann, M. (2011) Andromeda: a peptide search engine integrated into the MaxQuant environment. J Proteome Res 10, 1794-1805

50. Hourdel, V., Volant, S., O'Brien, D. P., Chenal, A., Chamot-Rooke, J., Dillies, M. A., and Brier, S. (2016) MEMHDX: An interactive tool to expedite the statistical validation and visualization of large HDX-MS datasets. Bioinformatics (Oxford, England)

51. Karst, J. C., Sotomayor-Perez, A. C., Ladant, D., and Chenal, A. (2012) Estimation of intrinsically disordered protein shape and time-averaged apparent hydration in native conditions by a combination of hydrodynamic methods. Methods in molecular biology 896, 163-177

52. Karimova, G., Pidoux, J., Ullmann, A., and Ladant, D. (1998) A bacterial two-hybrid system based on a reconstituted signal transduction pathway. Proc Natl Acad Sci U S A 95, 5752-5756

53. Sebo, P., Glaser, P., Sakamoto, H., and Ullmann, A. (1991) High-level synthesis of active adenylate cyclase toxin of Bordetella pertussis in a reconstructed Escherichia coli system. Gene 104, 19-24

54. Westrop, G. D., Hormozi, E. K., Da Costa, N. A., Parton, R., and Coote, J. G. (1996) Bordetella pertussis adenylate cyclase toxin: proCyaA and $\mathrm{CyaC}$ proteins synthesised separately in Escherichia coli produce active toxin in vitro. Gene 180, 91-99

55. Karimova, G., Fayolle, C., Gmira, S., Ullmann, A., Leclerc, C., and Ladant, D. (1998) Charge-dependent translocation of Bordetella pertussis adenylate cyclase toxin into eukaryotic cells: implication for the in vivo delivery of CD8(+) T cell epitopes into antigen-presenting cells. Proc Natl Acad Sci U S A 95, 12532-12537

56. Gmira, S., Karimova, G., and Ladant, D. (2001) Characterization of recombinant Bordetella pertussis adenylate cyclase toxins carrying passenger proteins. Res Microbiol 152, 889-900

57. El-Azami-El-Idrissi, M., Bauche, C., Loucka, J., Osicka, R., Sebo, P., Ladant, D., and Leclerc, C. (2003) Interaction of Bordetella pertussis adenylate cyclase with CD11b/CD18: Role of toxin acylation and identification of the main integrin interaction domain. J Biol Chem 278, 38514-38521

58. Semisotnov, G. V., Rodionova, N. A., Razgulyaev, O. I., Uversky, V. N., Gripas, A. F., and Gilmanshin, R. I. (1991) Study of the "molten globule" intermediate state in protein folding by a hydrophobic fluorescent probe. Biopolymers 31, 119-128

59. O'Brien, D. P., Brier, S., Ladant, D., Durand, D., Chenal, A., and Vachette, P. (2018) SEC-SAXS and HDX-MS: A powerful combination. The case of the calcium-binding domain of a bacterial toxin. Biotechnol Appl Biochem 65, 62-68 
Figure 1

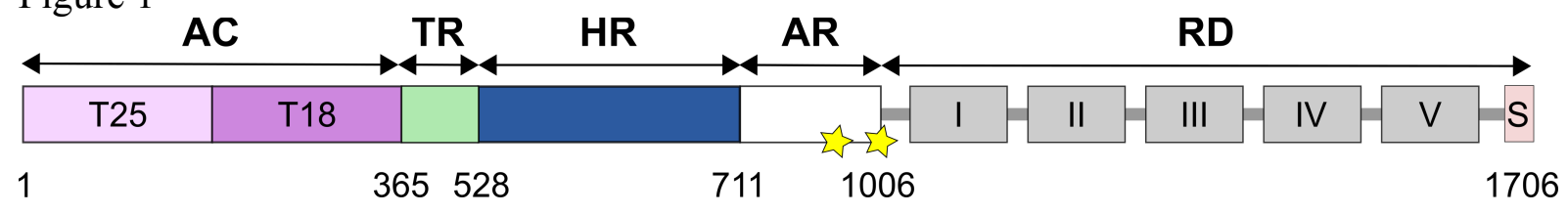


figure 2
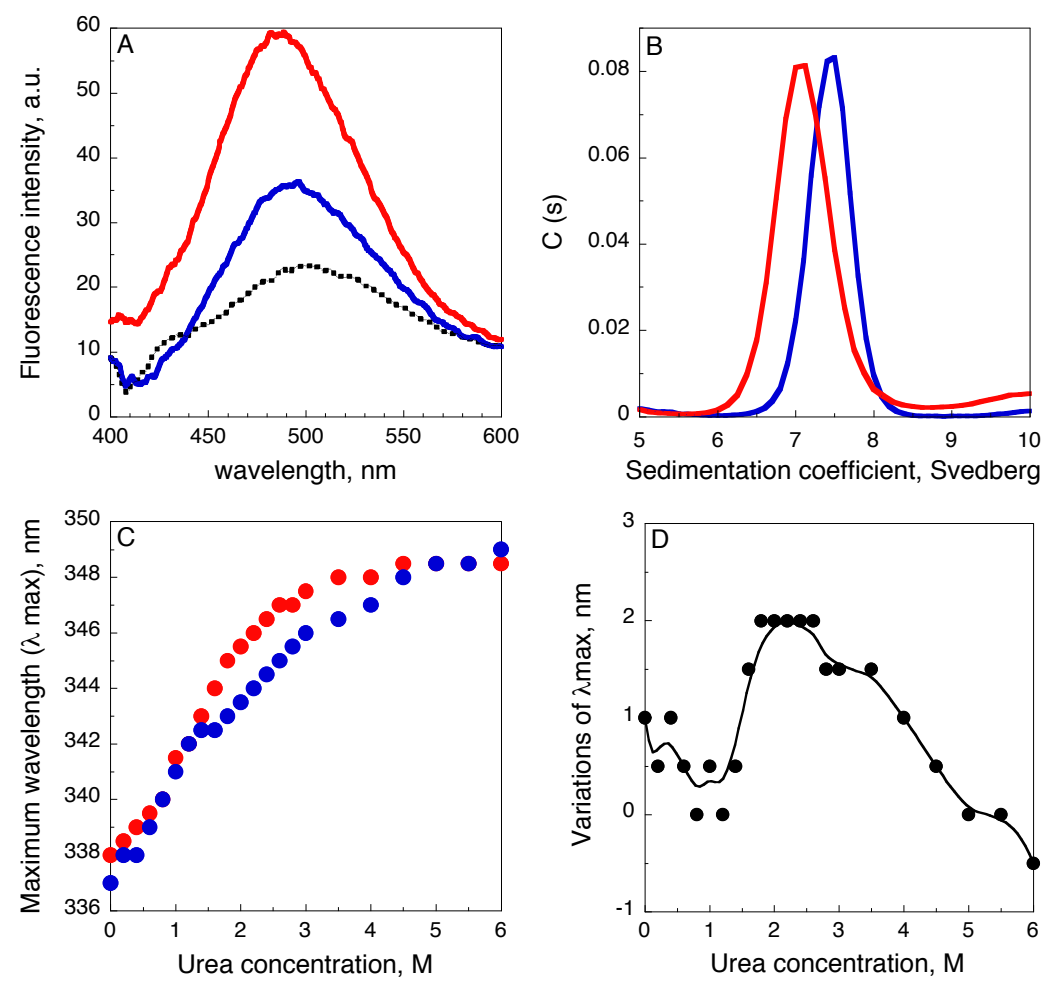

Figure 2 
figure 3

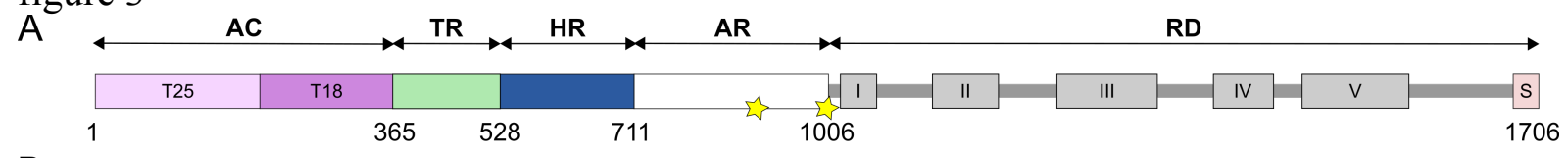

B

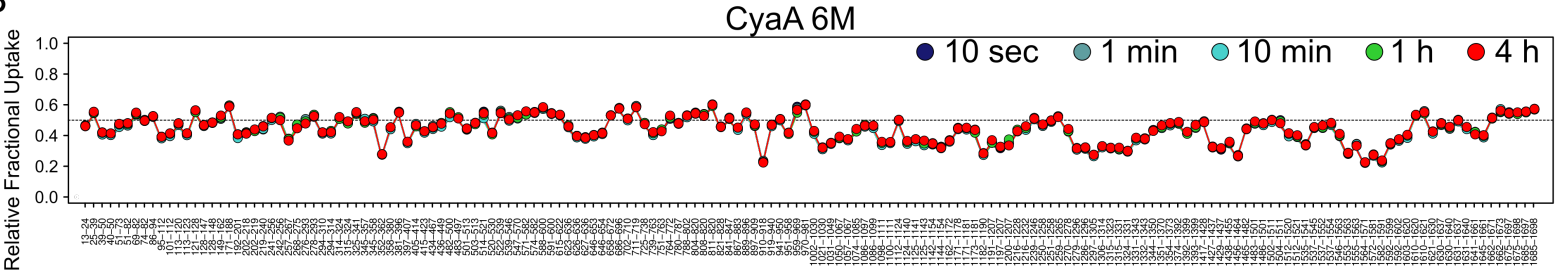

C

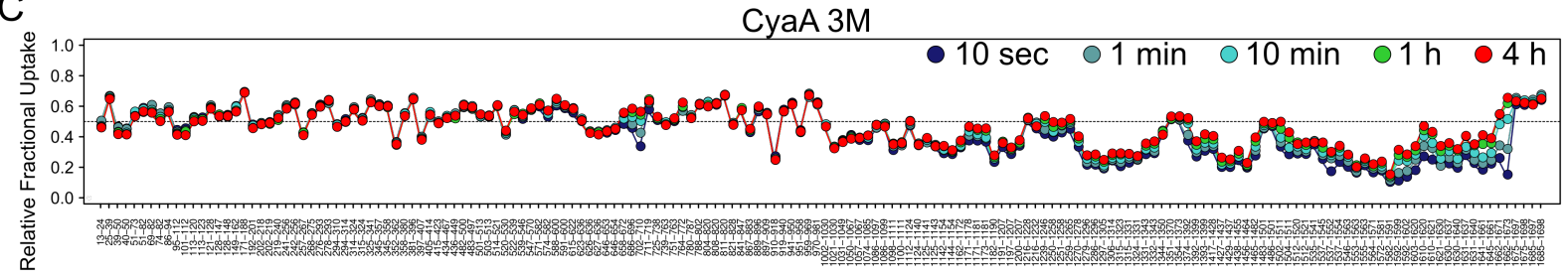

D

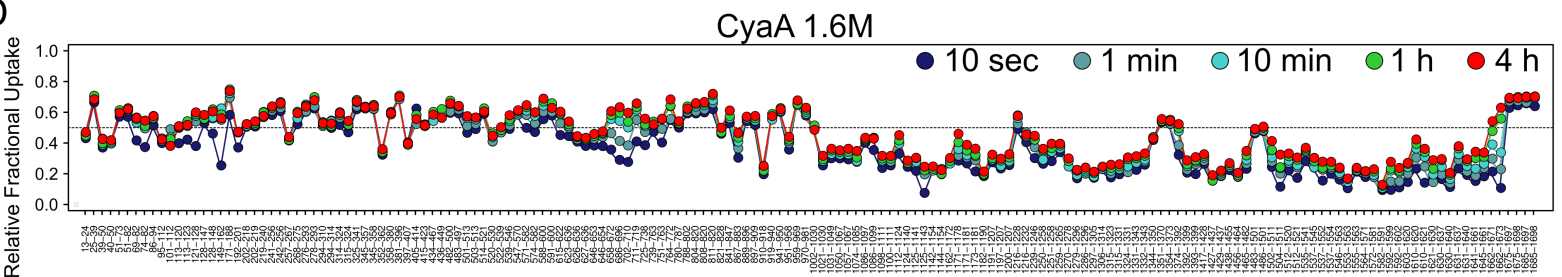

Peptides 
figure 4

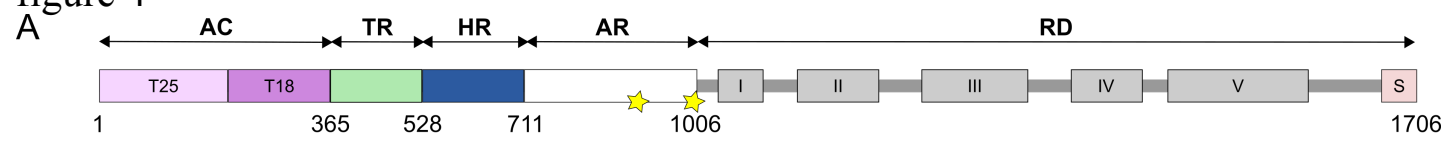

B

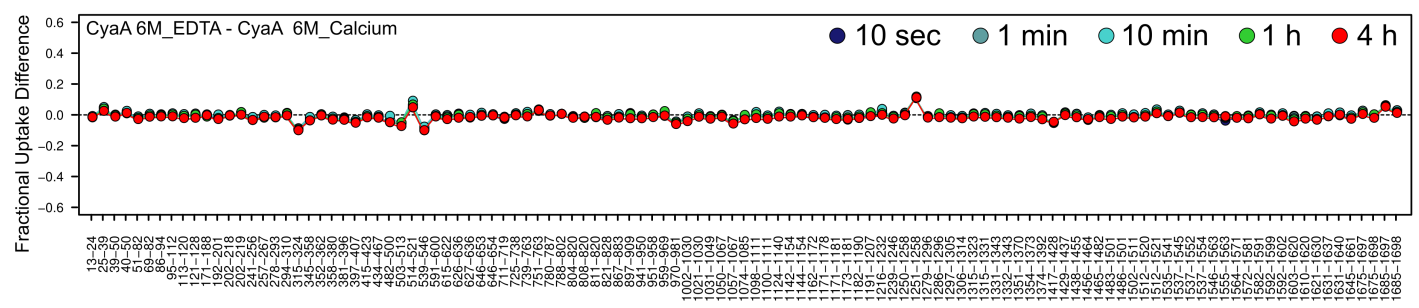

C

Peptides

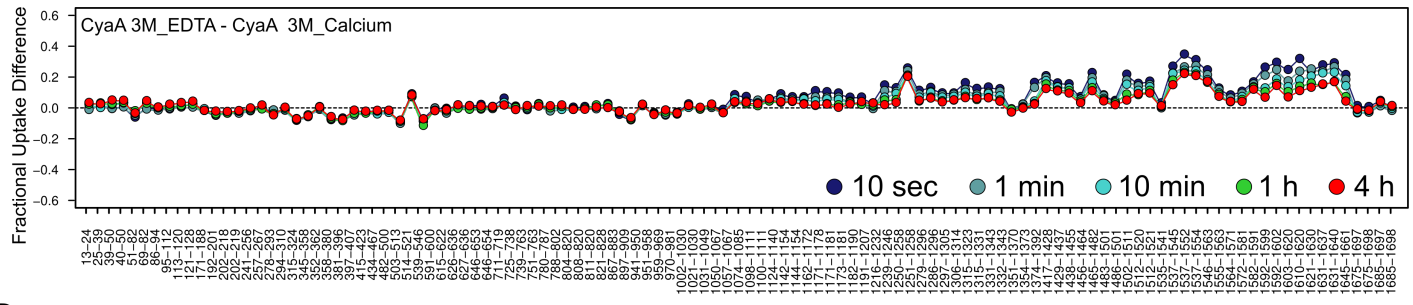

D Peptides

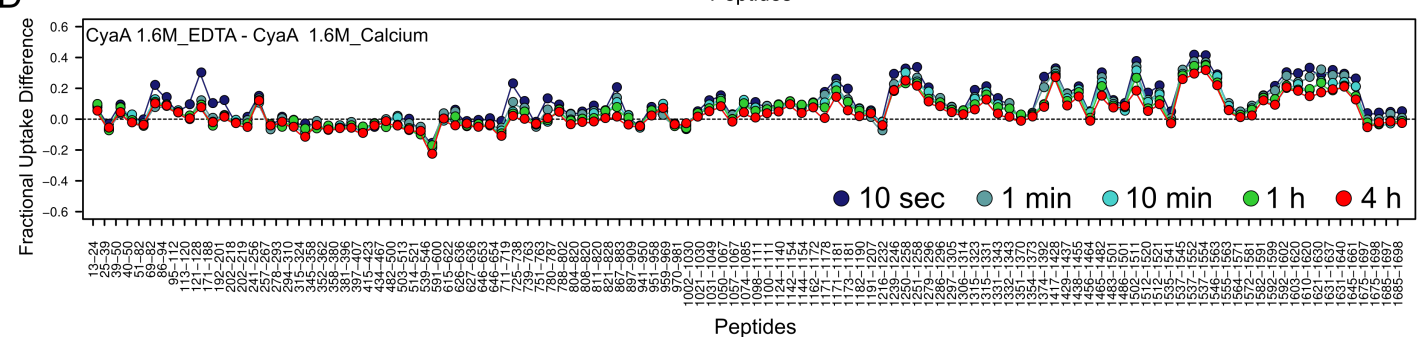


figure 5

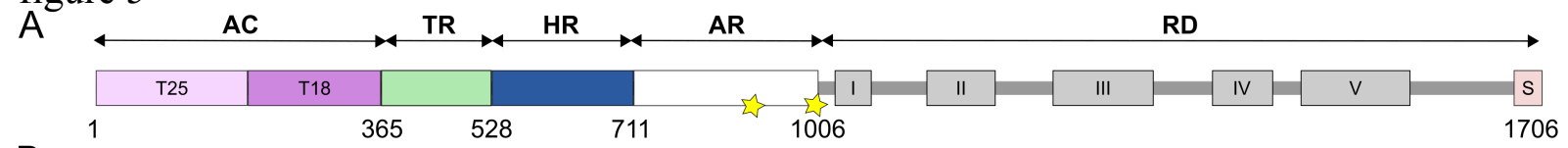

B

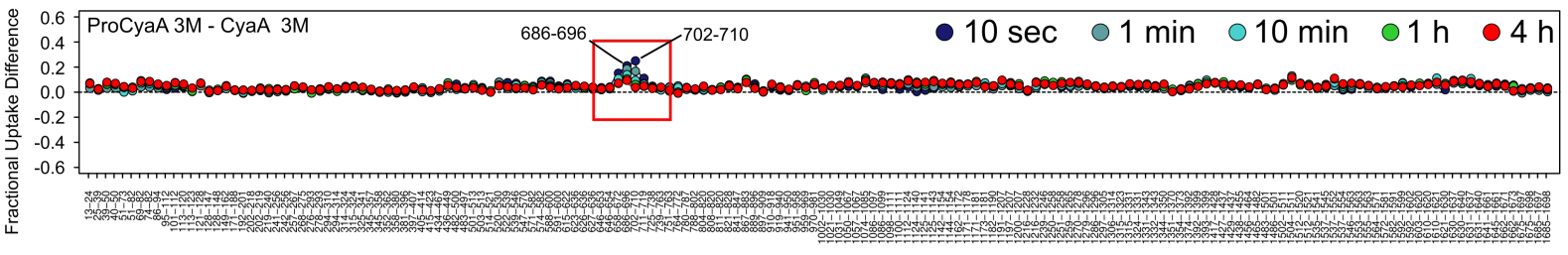

C Peptides

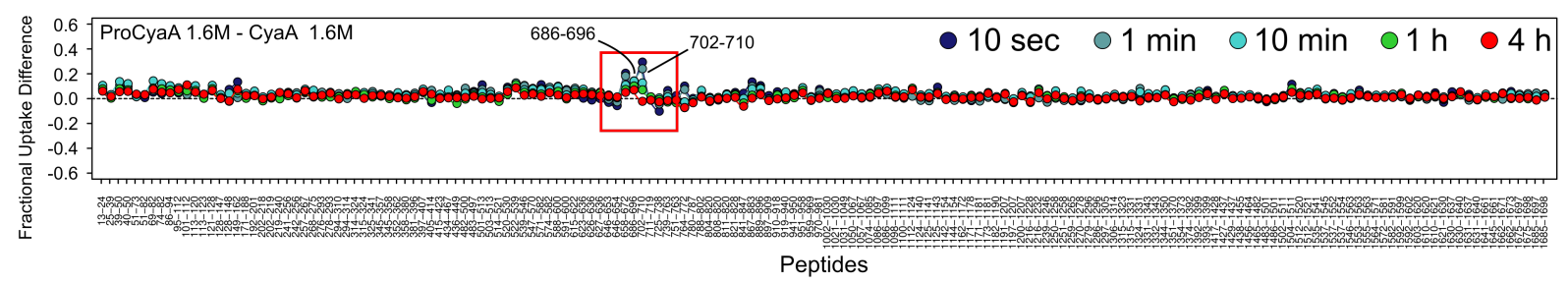

D
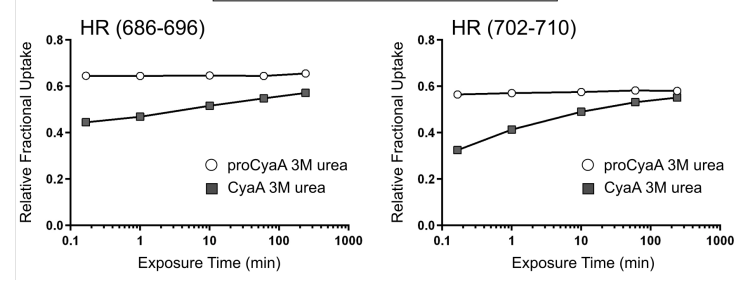

Proteins in $1.6 \mathrm{M}$ urea
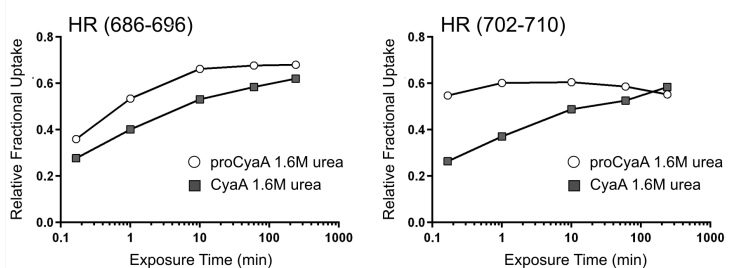
figure 6

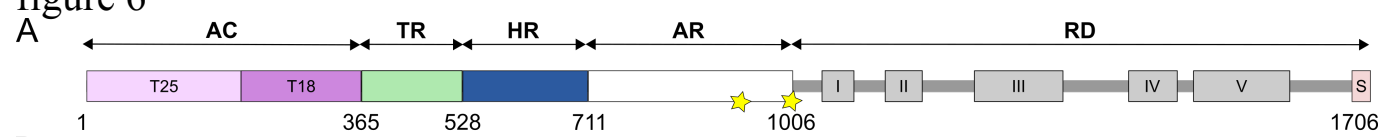

B

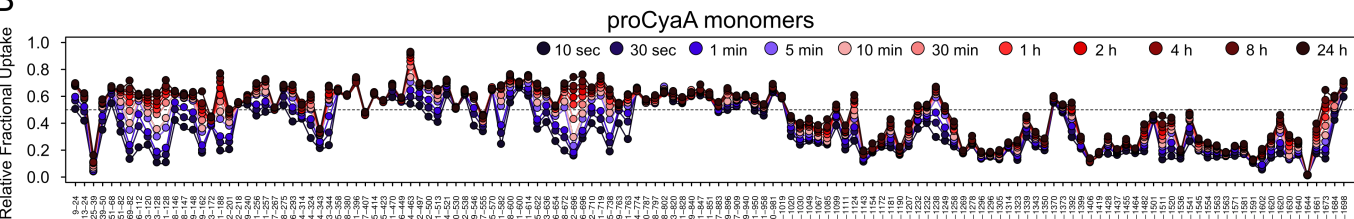

C

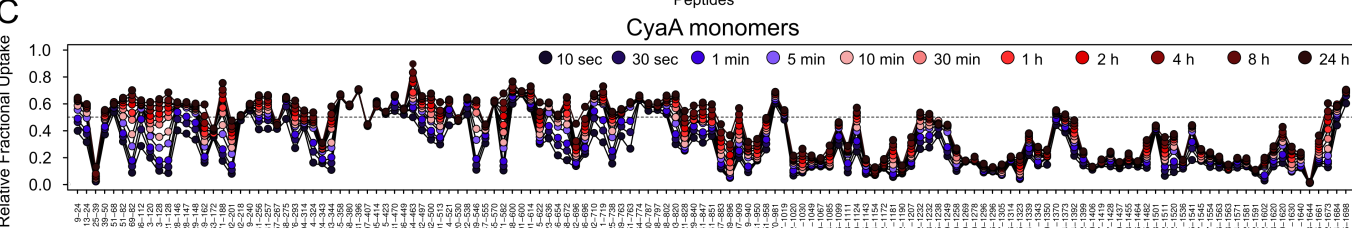

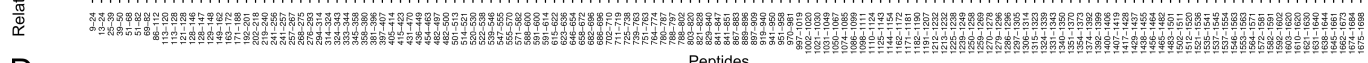

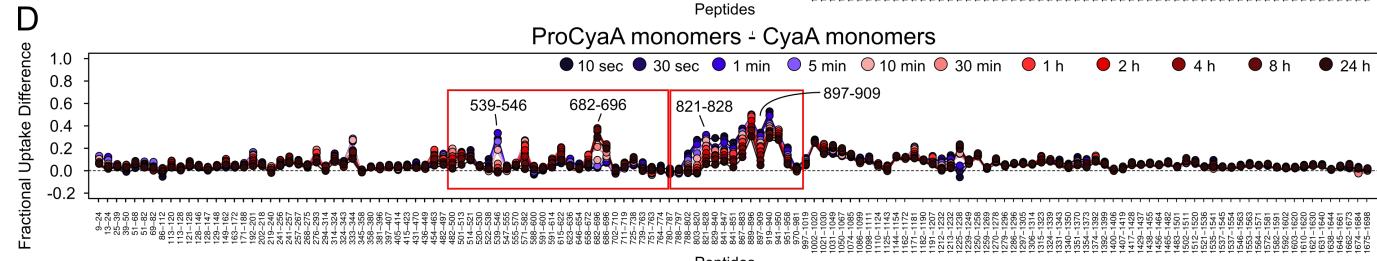

E

$$
\text { Peptides }
$$

R domain

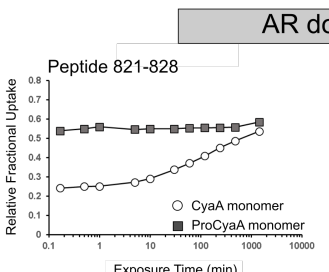

AR domain
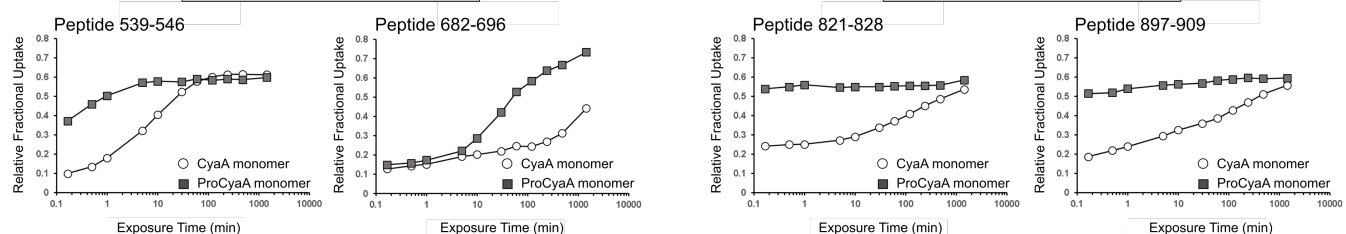